\title{
Ensino de Ciências
}





\section{Ensino de Botânica:}

\section{conhecimento e encantamento} na educação científica

SUZANA URSI ${ }^{I}$

PÉRCIA PAIVA BARBOSA II

PAULO TAKEO SANO III

- FLÁvio Augusto de SOUZA BERCHEZ IV

\section{Introdução}

$\mathrm{O}$ ENCANTAMENTO com o "fenômeno vida" esteve sempre presente ao longo de nossa existência. Desde a pré-história, os primeiros representantes de nossa espécie já analisavam formas e comportamentos dos outros seres de que dependiam para sobreviver, como as plantas e os animais de seu entorno. Em um passado menos remoto, autores clássicos, como Aristóteles e Theophrastus, discorreram sobre botânica e zoologia como temas importantes para o conhecimento. No Renascimento, um dos primeiros livros de biologia ilustrada é atribuído ao botânico Fuchs (1542). Hooke observou células na cortiça em 1665. A partir de então, muito conhecimento sobre a biologia tem sido construído. A classificação binomial foi inaugurada por Lineu, em 1735. Os naturalistas mostram-se protagonistas no século XIX, em que milhares de novas espécies foram descobertas e descritas. Em 1859, Charles Darwin, que cultivava e produziu ensaios sobre plantas carnívoras, publicou A origem das espécies, um dos textos impactantes da história da humanidade. Mendel, monge e botânico, é considerado o pai da genética, pelo seu trabalho com ervilhas, publicado em 1866.

Nos dias atuais, os séculos XX e XXI são considerados a "Era da Biologia" pelos inúmeros avanços científicos a ela relacionados. Nesse contexto, o trabalho de Watson e Crick (1953), explicando a estrutura do DNA, é uma das obras mais significativas, pois levou à manipulação genética, que tem mudado nosso dia a dia. Atualmente, somos capazes de modificar a Terra de forma estrondosa; causando, inclusive, impactos ambientais indesejados. Mais uma vez, a biologia entra em cena como ciência para mitigação de tais impactos, auxiliando na reflexão sobre como a humanidade encaminha seu futuro e o de todas as demais espécies do planeta. Diante desse cenário, torna-se incontestável que a abordagem dessa ciência na Educação Básica é fundamental na formação plena dos estudantes e futuros cidadãos. 
Dentre as áreas que constituem a biologia, a botânica, cuja notória relevância foi discutida por Salatino e Buckeridge (2016), é o nosso foco. As discussões sobre o ensino desse tema estão em sintonia com os pensamentos referentes ao processo de ensino-aprendizagem da Biologia como um todo. Contudo, o ensino de Botânica apresenta peculiaridades que justificam um olhar mais cuidadoso e específico para suas questões. Este artigo tem como objetivo justamente favorecer tal abordagem, apresentando reflexões sobre objetivos, desafios e possibilidades para o enfoque do ensino de Botânica na Educação Básica, um enfoque que produza conhecimento e encantamento.

\section{Objetivos do ensino de Botânica na Educação Básica}

Iniciamos nossa reflexão estimulando uma superação da visão estritamente propedêutica de ensino; nela, um nível da educação é pensado apenas como etapa preparatória para o próximo nível. Ao contrário, defendemos que aprender biologia, incluindo botânica, pode ampliar o repertório conceitual e cultural dos estudantes, auxiliando na análise crítica de situações reais e na tomada de decisões mais consciente, formando cidadãos mais reflexivos e capazes de modificar sua realidade. Ter subsídios científicos, superando o senso comum, pode auxiliar de forma decisiva nas atitudes dos cidadãos. Nurse (2016), em "The Importance of Biology Education", destaca que tal educação deve ajudar as pessoas a fazer escolhas informadas, ter maior engajamento no desenvolvimento científico e tecnológico e preparar-se para o trabalho em uma economia desenvolvida. Isso envolve inúmeras questões, inclusive do cotidiano, tais como escolher o alimento a ser comprado; quais fontes de energia utilizar; ou que políticas apoiar para lidar com as mudanças climáticas, o uso de células-tronco ou a manipulação genômica. Muitos dos documentos norteadores da educação no Brasil vêm adotando visão semelhante (ex. Brasil, 2006).

Nessa perspectiva, o ensino de Biologia visa que o estudante aprenda conceitos e processos fundamentais da área, compreenda a natureza e o processo de construção do conhecimento científico e seja capaz de analisar criticamente as implicações da Ciência e da Tecnologia na sociedade. Assim, espera-se promover a Alfabetização Científica dos aprendizes (Hurd, 1998). Krasilchik (2008) destaca que, para tanto, algumas dimensões devem ser consideradas. Estimulados por nossa experiência no trato com questões relacionadas à Percepção Ambiental, bem como por estudos da área (Chenoweth; Gobster, 1990; Seniciato; Cavassan, 2009; White, 1977), julgamos pertinente acrescentar uma quinta dimensão, a estética, às quatro primeiras já propostas pela autora:

- Ambiental - motivando a análise do impacto da atividade humana no meio ambiente e a busca de soluções para os problemas decorrentes;

- Filosófica, cultural e histórica - levando à compreensão do papel da ciência na evolução da humanidade e sua relação com religião, economia, tecnologia, entre outros;

- Ética - estimulando a análise e argumentação sobre assuntos polêmicos 
vinculados às questões científicas que são divulgados pelos meios de comunicação em massa, como aborto, eutanásia, biodiversidade e relações internacionais, propriedade de descobertas científicas, entre outros;

- Médica - auxiliando a compreensão de conceitos biológicos básicos que estão estreitamente relacionados a prevenção e cura de doenças.

- Estética - promovendo a percepção do ambiente e sua biodiversidade pautando-se na integração entre razão-imaginação-sentimentos-emoções, resultando em valores e atitudes potencialmente transformadores do cotidiano.

O ensino de Botânica insere-se nesse cenário, apresentando objetivos e conteúdos conceituais, procedimentais e atitudinais capazes de contribuir com todas essas dimensões (Quadro 1 - exemplos que, no entanto, não esgotam a grande quantidade de outras possibilidades).

Quadro 1 - Exemplos de objetivos e conteúdos nas diferentes Dimensões do Ensino de Botânica

\section{Dimensões do Ensino de Botânica}

\section{Ambiental}

As plantas são constituintes chaves do ambiente, estando relacionadas a inúmeros processos ecológicos e serviços ecossistêmicos. Estão entre os organismos mais ameaçados pelo crescimento populacional, que gera poluição e exploração pouco racional de recursos. Compreender e discutir tais temas pode subsidiar os estudantes em seus posicionamentos sobre importantes questões ambientais da atualidade.

\section{Filosófica, cultural, histórica}

O vínculo entre as plantas e aspectos culturais de nossa espécie é notório. Podemos listar diversas plantas que mudaram nossa história, por suas aplicações na alimentação, na medicina, no vestuário, no paisagismo, dentre outras. Se pensarmos nas artes, percebemos a importância da representação das plantas em nosso cotidiano e ao longo da história.

\section{Médica}

O uso medicinal tradicional das plantas é contundente, mas também sua exploração para o isolamento de princípios ativos e uso em muitos dos medicamentos industrializados atualmente utilizados. Por outro lado, crenças populares equivocadas, que gerem o uso indiscriminado das plantas, podem oferecer riscos à saúde.

\section{Ética}

Botânica e Biotecnologia estão intimamente relacionadas, com alguns dos maiores avanços relacionados à interação entre vegetais e microrganismos. Muitos dos temas mais urgentes e/ou polêmicos da atualidade relacionam-se em algum grau à Botânica, como uso de organismos transgênicos, mudanças climáticas globais, legalização de alguns tipos de drogas atualmente consideradas ilícitas, exploração agrícola, conservação e perda da biodiversidade, energias alternativas, dentre outros.

\section{Estética}

A convivência e a apreciação das plantas são reconhecidamente importantes promotores de bem-estar. Perceber a diversidade vegetal, bem como criar conexão com tais organismos, podem ser considerados passos essenciais para a valorização e conservação ambiental, questão tão relevante na atualidade. 
Além dos aspectos atitudinais enfocados acima, é evidente que alguns dos conceitos e processos mais centrais do conhecimento biológico fazem parte do escopo da botânica (como fotossíntese, teia alimentar, fluxo de energia, classificação da biodiversidade e evolução). Diante disso, enfatizamos que um objetivo essencial do ensino de Botânica é promover o entendimento efetivo desses conceitos e processos, para além do enfoque meramente memorístico, baseando-o na construção de conhecimento pelos estudantes e integrando-o às demais áreas de conhecimento.

Ainda: a aprendizagem de conteúdos procedimentais como objetivo do ensino de Botânica aproxima os estudantes do "fazer científico". O material biológico vegetal é muito adequado para diversas atividades práticas (Santos et al., 2012), o que se torna um estímulo adicional para promover a habilidade de realizar investigações científica. Outra habilidade refere-se a compreender os procedimentos da classificação biológica. Não se trata de decorar critérios ou características de grupos vegetais, mas sim entender os procedimentos gerais utilizados na organização da diversidade vegetal, enfatizando a importância que os eventos evolutivos apresentam na atualidade, principalmente relacionados à sistemática filogenética. Capacidades de observação e de representação são outras importantes habilidades relacionadas à Botânica, que permitem analisar os organismos destacando suas peculiaridades e reconhecendo semelhanças. Assim também, interpretar estruturas tridimensionais constitui uma habilidade essencial para compreender anatomia vegetal e a relação forma-função em plantas, conforme discute Ceccantini (2006).

Essas reflexões sobre os objetivos do ensino de Botânica que almejamos estão sistematizadas na Figura 1. De novo: não esgotamos as possibilidades, mas apresentamos um cenário para reflexão.

\section{Desafios a serem superados}

A abordagem da botânica na Educação Básica, em muitos casos, ainda está distante de alcançar os objetivos esperados em um processo de ensino-aprendizagem realmente significativo e transformador. Relata-se, muitas vezes, que os estudantes, e até mesmo seus professores, não se interessam pela botânica, que é considerada difícil, enfadonha e distante de sua realidade. Esse não é um fenômeno apenas nacional, pois trabalhos acadêmicos têm discutido tais aspectos em diferentes lugares (Hershey, 1996; Silva; Ghilardi-Lopes, 2014). Alguns deles estão resumidos na Figura 2. 


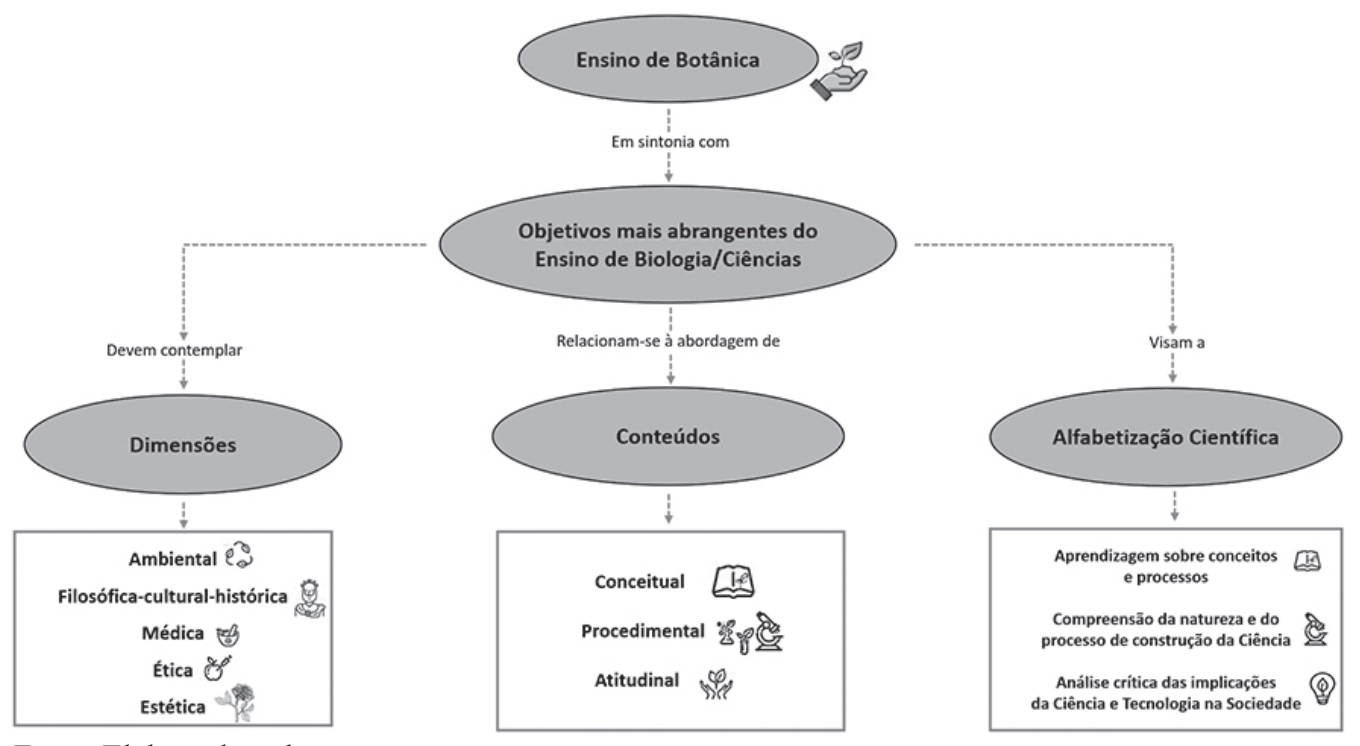

Fonte: Elaborada pelos autores.

Figura 1 - Objetivos do ensino de Botânica, destacando sua relação com os objetivos e conteúdos mais abrangentes do ensino de Biologia e de Ciências na Educação Básica.

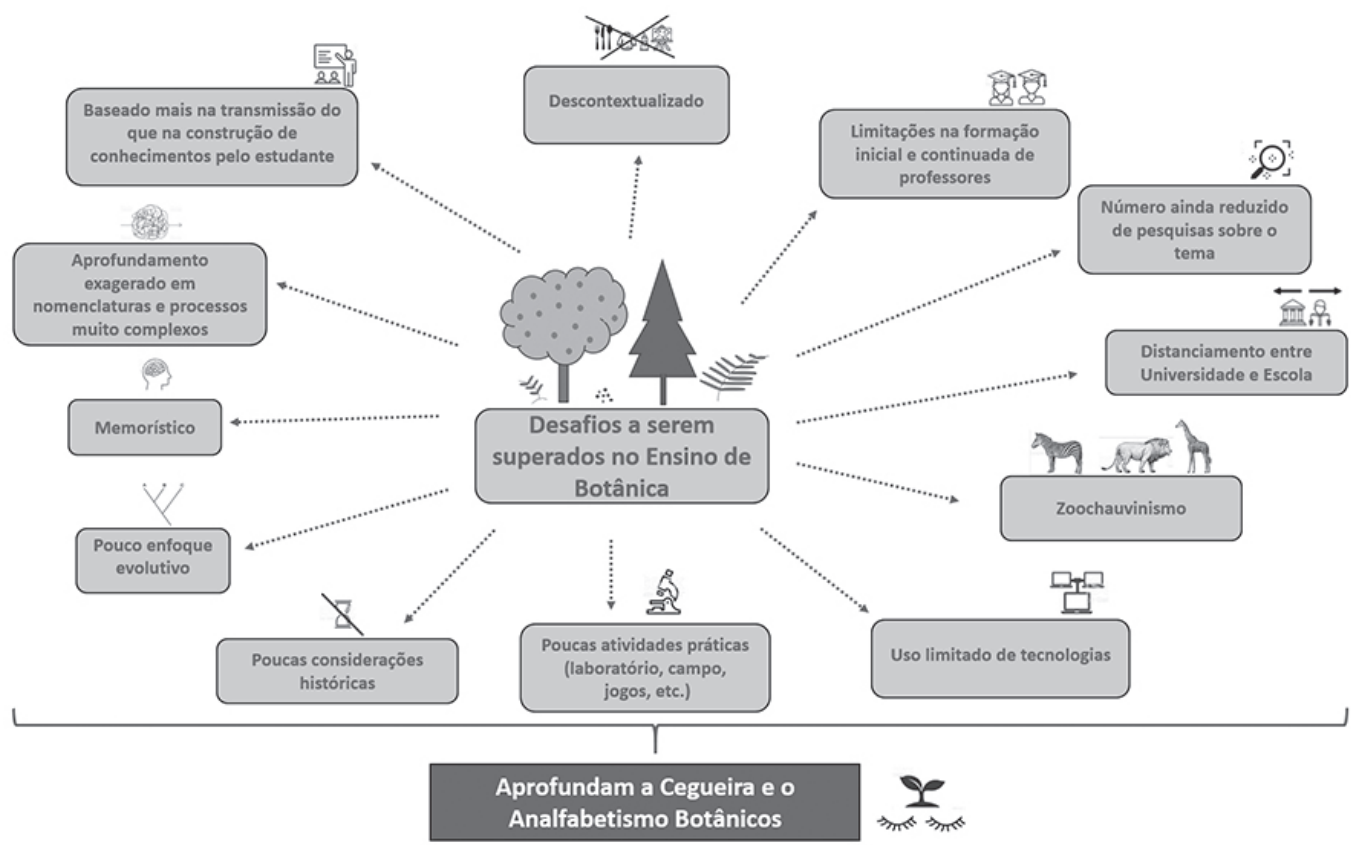

Fonte: Elaborada pelos autores.

Figura 2 - Principais desafios a serem superados no ensino de Botânica. 
Quanto às abordagens e estratégias didáticas utilizadas, em muitas circunstâncias empreende-se o ensino de Botânica de forma descontextualizada, sendo esse provavelmente um dos fatores que causam maior desinteresse e dificuldade de aprendizagem por parte dos estudantes. A falta de atividades práticas de diferentes naturezas e o uso limitado de tecnologias, especialmente as digitais, tão familiares aos estudantes, também representam obstáculos. Outro ponto especialmente importante para a botânica é a presença de enfoque evolutivo, capaz de dar mais coerência ao estudo da classificação vegetal. Infelizmente, tal abordagem não é a predominante e, mesmo no Ensino Superior, detectam-se lacunas conceituais (Bizotto et al., 2016). Kinoshita et al. (2006) alertam que, a exemplo do que ocorre em outras áreas do conhecimento, muitas vezes o ensino de Botânica é baseado em métodos tradicionais que priorizam reprodução e memorização de nomes e conceitos em detrimento do questionamento, sendo também muito teórico e desestimulante para o estudante. Santos (2006), pesquisando a inserção de temas botânicos no Ensino Médio, conclui que a abordagem botânica, em geral, abstém-se de seu caráter histórico. Já Macedo et al. (2012), investigando a percepção de professores sobre as dificuldades de seus estudantes, apontam como maiores desafios a nomenclatura complexa da área, o desinteresse dos aprendizes, assim como alguns temas específicos: ciclo de vida e fisiologia. Por outro lado, Towata et al. (2010) evidenciam que, para o Ensino Fundamental, as experiências com a botânica tendem a ser mais positivas, com estratégias de ensino mais dinâmicas. As autoras discutem que a pressão do vestibular parece ser um agravante importante no Ensino Médio.

Os desafios supracitados somam-se e são intensificados por outros, como o "zoochauvinismo": os vegetais geralmente são negligenciados nos materiais didáticos, que trazem mais exemplos relacionados à zoologia, por considerar os animais mais atrativos para os estudantes (Balas; Momsen, 2014). Um caso grave refere-se à Base Nacional Comum Curricular (BNCC), em que poucos exemplos botânicos são encontrados (Brasil, 2017). Nesse cenário, é importante promovermos um movimento de resistência e valorização das plantas e de seu ensino.

Algumas explicações relacionam essa desvalorização a fatores como: aspectos biológicos e culturais do ser humano (percepção do ambiente, instintos de caça e defesa), processo de urbanização e até a pouca atenção que as plantas recebem dos meios de comunicação em geral (Hershey, 2002; Salatino; Buckeridge, 2016; Wandersee; Schussler, 1999; 2002). Encontramos raízes para os problemas também no próprio contexto universitário, no qual as disciplinas voltadas à botânica são muito focadas em conteúdos conceituais e desenvolvidas por meio de métodos tradicionais de ensino, embora experiências inovadoras eventualmente aconteçam (Silva, 2013). Além disso, nos cursos que formam bacharéis e licenciados, em muitos casos, pouca atenção é dada, pelos docentes, para a formação dos futuros professores de Biologia e Ciências, já que a ênfase 
recai na formação dos bacharéis (Silva et al., 2006). Por outro lado, corre-se o risco dos futuros professores aprenderem sobre aspectos didáticos, porém de forma desarticulada com o conteúdo conceitual a ser ministrado.

Estimula-se pouco que seja desenvolvido o Conhecimento Pedagógico do Conteúdo (PCK - Pedagogical Content Knowledge), conceito proposto por Shulman (1986) que representa a união entre conhecimentos referentes aos conteúdos específicos (como a botânica) e os pedagógicos. Tal união permite ao professor compreender como determinados tópicos são organizados, representados e adaptados aos diversos interesses e habilidades dos alunos, podendo assim ser ensinados e compreendidos. Consideramos que o desenvolvimento do PCK de botânica deve ser um ponto de destaque nos cursos de formação que tenham como meta realmente interromper o ciclo de desvalorização, levando à formação de professores qualificados, que se interessam, conhecem e se sentem seguros para ensinar tal temática.

Destacamos, como mais um ponto relevante, o número ainda reduzido de pesquisas sobre o ensino de Botânica, quando comparado às demais áreas do conhecimento biológico. A qualidade é outra questão, pois, em muitos casos, os trabalhos apresentam uma visão muito "mecanicista" de ensino-aprendizagem (Silva et al., 2006). Devemos realizar pesquisas de caráter mais abrangentes e sintonizadas com as múltiplas necessidades da área. Além disso, é necessário que tais pesquisas sejam conhecidas e discutidas pelos professores, para que se tornem parceiros nessas iniciativas. Enfatizamos a necessidade de aproximação entre universidade e escola, possibilitando experiências ricas, capazes de auxiliar na superação dos desafios aqui abordados (Kinoshita et al., 2006; Macedo; Ursi, 2016).

A partir desse cenário, percebemos que os diversos desafios contribuem para causar e agravar a chamada "Cegueira Botânica", que remete ao fato de as pessoas apresentarem, em geral, pouca percepção sobre as plantas que as circundam, com "sintomas" como a desatenção em relação às plantas presentes no cotidiano, a ideia de que os vegetais são apenas cenário para a vida animal e a falta de compreensão sobre o papel dos vegetais no ciclo do carbono (Wandersee; Schussler, 1999; 2002). Outro reflexo relaciona-se ao que Uno (2009) denomina "Analfabetismo Botânico", ligado à falta não só de interesse pela temática, mas também de conhecimento, em diferentes níveis (dos mais pontuais e simples até os mais abrangentes e complexos). Em um processo de retroalimentação, a Cegueira e o Analfabetismo Botânicos são fomentados pelo ensino desestimulante e pouco significativo. Por outro lado, esses dois fatores contribuem para dificultar ainda mais o ensino de Botânica. Assim, é necessário discutirmos sobre possibilidades pedagógicas capazes de aproximar a botânica dos estudantes e de seus professores, fazendo que o processo de seu ensino-aprendizagem seja mais motivador e efetivo. 


\section{Contextualização e seu potencial para o ensino de Botânica}

Apesar dos desafios identificados, podemos relatar e discutir sobre uma grande quantidade de experiências bem-sucedidas relacionadas à abordagem da botânica na Educação Básica. Um ponto que todas têm em comum é a contextualização (Quadro 2), principalmente quando aliada à utilização de uma variedade de estratégias didáticas mais dinâmicas, que propiciem o protagonismo do estudante. Assim, enfocamos a contextualização como eixo norteador das reflexões que se seguem, porém, reconhecendo que outros aspectos são igualmente importantes, alguns deles evidenciados na Figura 3.

A relevância do ensino contextualizado sustenta-se em um dos pressupostos mais amplamente aceitos por pesquisadores das áreas de neurociência, psicologia e pedagogia: as pessoas elaboram o novo conhecimento com base naqueles que já possuem (Bransford et al., 2007). Dessa forma, é mais interessante partir desses conhecimentos e compará-los, ampliá-los, do que iniciar um novo tema de forma independente. A contextualização também torna o processo mais interessante aos olhos dos aprendizes, que conseguem atribuir sentido ao que estudam.

A contextualização estimula o papel de protagonista e a postura autônoma do estudante. Não obstante, o professor continua sendo mediador fundamental do processo ensino-aprendizagem. É ele o responsável por identificar os conhecimentos prévios e o contexto dos alunos, organizar o currículo baseando-se nesses elementos e escolher as melhores estratégias de ensino e avaliação. É importante destacar que a contextualização não deve representar uma limitação, um engessamento do ensino à realidade imediata do aluno. Ela deve possibilitar que, partindo de sua realidade, tal aluno conheça outros horizontes e novas possibilidades de aprender.

No Quadro 3, partimos de alguns tipos de contextualização sociocultural da Ciência e Tecnologia (Brasil, 1999) e os relacionamos a maneiras possíveis de abordar assuntos tratados no escopo da botânica. Nota-se que é possível levantar questionamentos que auxiliem os estudantes a expressarem suas crenças e seus conhecimentos prévios sobre os assuntos tratados, dando suporte à aprendizagem do novo tema da botânica a ser abordado. As possibilidades de contextualização são inúmeras. Pode-se abordar a vegetação presente na escola ou seu entorno (Franco; Ursi, 2014), a relação das plantas com a biotecnologia (Dandalo et al., 2014), com a arte (Ursi; Barbosa, 2014), com o cotidiano (Barbosa et al., 2016), dentre outros. Espaços não formais de ensino também constituem boas alternativas para empreender o ensino em contextos diferenciados, como museus, jardins botânicos e Unidades de Conservação (Berchez et al., 2016). 
De forma geral, é o ato de vincular o conhecimento à sua origem e à sua aplicação.

A ideia de contextualização entrou em pauta com a reforma do ensino médio, a partir da Lei de Diretrizes e Bases da Educação, de 1996, que orienta para a compreensão dos conhecimentos para uso cotidiano. Tem origem nas diretrizes que estão definidas nos Parâmetros Curriculares Nacionais, que são guias para orientar a escola e os professores na aplicação do novo modelo. De acordo com esses documentos, orienta-se para uma organização curricular que, entre outras coisas, trate os conteúdos de ensino de modo contextualizado, aproveitando sempre as relações entre conteúdos e contexto para dar significado ao aprendido, estimular o protagonismo do aluno e estimulá-lo a ter autonomia intelectual.

Portanto, o novo currículo, segundo orientação do Ministério da Educação (MEC), está estruturado sobre os eixos da interdisciplinaridade e da contextualização, sendo que esta última vai exigir que "todo conhecimento tenha como ponto de partida a experiência do estudante, o contexto onde está inserido e onde ele vai atuar como trabalhador, cidadão, um agente ativo de sua comunidade". A contextualização também pode ser entendida como um tipo de interdisciplinaridade, na medida em que aponta para o tratamento de certos conteúdos como contexto de outros.

A ideia da contextualização requer a intervenção do estudante em todo o processo de aprendizagem, fazendo as conexões entre os conhecimentos. De acordo com o MEC, "esse aluno que estará na vanguarda não será nunca um expectador, um acumulador de conhecimentos, mas um agente transformador de si mesmo e do mundo".

Trabalhando contextos que tenham significado para o aluno e possam mobilizá-lo a aprender, num processo ativo, em que ele é protagonista, acredita-se que o aluno tenha um envolvimento não só intelectual, mas também afetivo. Isso, de acordo com o novo currículo, seria educar para a vida.

Fonte: Menezes; Santos (2001).

\section{Quadro 3 - Tipos e definições de contextualização e possíveis relações com temas abordados no ensino de Botânica}

\begin{tabular}{|l|c|}
\hline \multicolumn{2}{|c|}{ Contertualização sociocultural da Ciência e Tecnologia: } \\
enfoque em temas botânicos
\end{tabular}




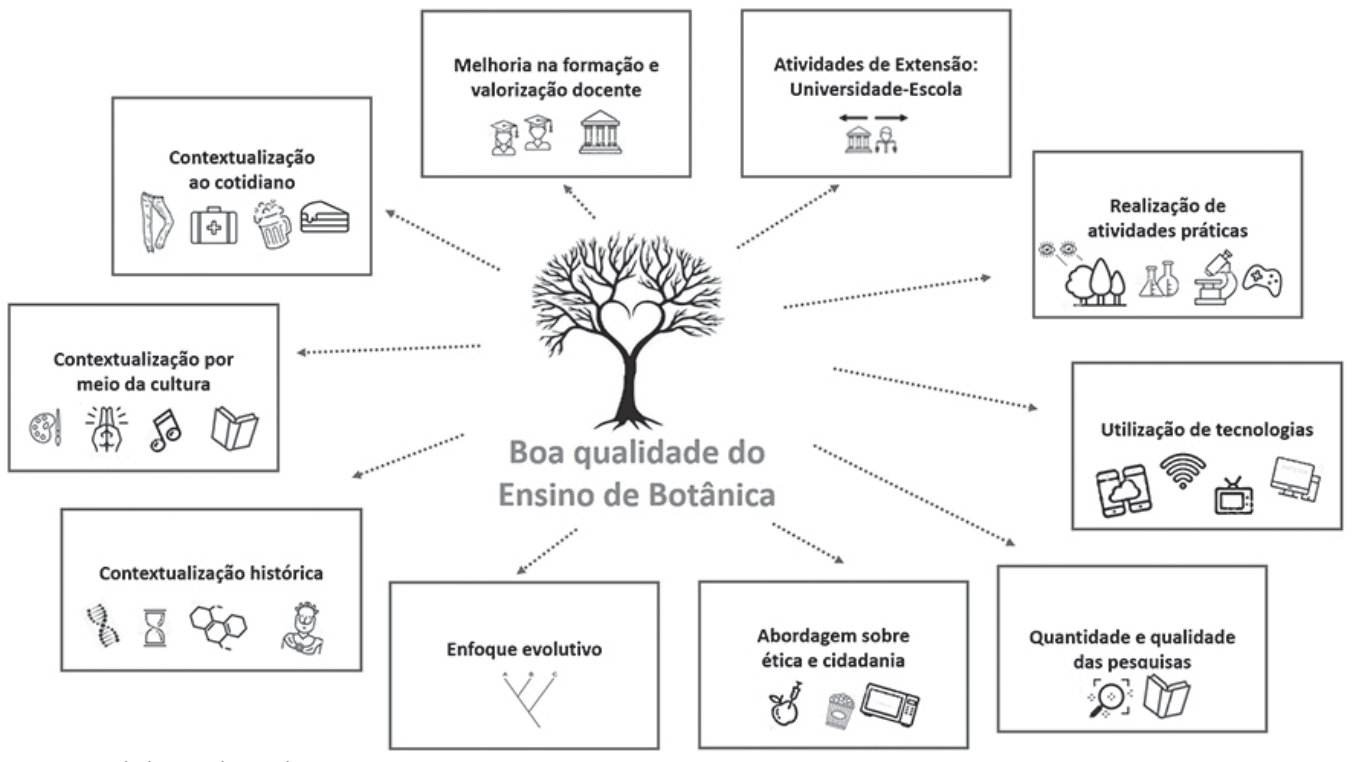

Fonte: Elaborada pelos autores.

Figura 3 - Alguns elementos relacionados à promoção da boa qualidade do ensino de Botânica na Educação Básica.

\section{Relatos de experiências: aproximação entre Universidade e Escola}

Os docentes do Departamento de Botânica do IB/USP historicamente têm dedicado atenção à abordagem da botânica na Educação Básica. Isso pode ser evidenciado na execução de diversas atividades de extensão, oferecimento de disciplinas para a Licenciatura e publicações na área (Santos et al., 2012). No Departamento, a área de ensino de Botânica é formada por três docentes (todos eles, autores no presente trabalho), atuando em nível de graduação, pós-graduação, pesquisa e extensão. Reservamos esta última parte de nossa reflexão para apresentar brevemente algumas de nossas iniciativas, que buscam estimular a melhoria na qualidade do ensino de Botânica por meio da aproximação entre Universidade e Escola. Em sintonia com o que discutimos no último tópico, trazemos experiências que visam promover o ensino contextualizado por meio de estratégias diversificadas.

Assim, concluímos o presente esforço de pensar sobre a situação do ensino de Botânica na Educação Básica, esperando que as reflexões e experiências aqui apresentadas ampliem as discussões e fomentem o diálogo, gerando cada vez mais conhecimento e promovendo transformações positivas no ensino de Botânica.

\section{Formação de professores na Educação a Distância}

O BotEd, "Grupo de Pesquisa Botânica na Educação", desenvolve pesquisas especialmente sobre duas temáticas: Percepção/Educação Ambiental e Formação docente. Atualmente, utilizamos as ideias de Shulman et al. sobre PCK e conhecimentos docentes como nosso principal referencial teórico. Elabo- 
ramos, aplicamos e avaliamos estratégias e recursos didáticos diversos para o ensino-aprendizado contextualizado de botânica. Participam do grupo a docente coordenadora, estudantes de graduação e pós-graduação e professores da Educação Básica que empreendem a atividade como formação continuada (alguns são também estudantes). Essa convivência nos ajuda a manter uma perspectiva de pesquisa que incorpora de forma integrada tanto os arcabouços teóricos da área de pesquisa em ensino, quanto as situações reais vivenciadas nas escolas. Nossas atividades e produções, bem como a de muitos outros colegas, podem ser acessadas no site Botânica Online,${ }^{1}$ que tem como objetivo ser um "ponto de encontro" real para os interessados em ensino de Botânica. Consideramos a organização e a manutenção desse site uma importante iniciativa de extensão de nosso grupo.

No contexto de atuação do BotEd, participamos, nos últimos anos, de três das mais importantes iniciativas para a formação de professores de Ciências/Biologia na modalidade Educação a Distância envolvendo as universidades públicas do estado de São Paulo. Uma voltada à formação continuada (Curso de Especialização para Docentes de Biologia da RedeFor) e duas voltadas à formação inicial (Licenciatura em Ciências e Matemática - USP/Univesp e Licenciatura em Biologia - Univesp). Apesar das dificuldades da modalidade, a Educação a Distância é uma realidade da qual não podemos (e provavelmente não devemos) escapar, crescente nos dias de hoje e que também apresenta possibilidade pedagógicas interessantes (Ursi, 2017). Nesse sentido, ao atuarmos em diferentes disciplinas dos cursos citados, desenvolvemos inúmeras atividades, tanto para fomentar a aprendizagem dos professores em formação, quanto para que eles as adaptem e utilizem com seus estudantes. Compartilhamos resumidamente duas dessas experiências, que são tratadas com maior detalhamento por Ursi (2017) e Ursi e Barbosa (2014).

\section{Herbário virtual}

A disciplina "Práticas para o Ensino de Biologia I" da Licenciatura em Biologia (Univesp) focava-se no ensino de Biodiversidade e um de nossos principais desafios foi buscar alternativas para realizar atividades práticas e contextualizadas à distância. Propusemos a realização de um Herbário Virtual. Os estudantes foram orientados a escolherem dez plantas com relevância em seu cotidiano. Inicialmente, elaboraram uma apresentação em arquivo tipo power-point com informações gerais sobre tais plantas, bem como com justificativas para sua escolha. Depois, realizaram todas as etapas da confecção de herbários, já abordadas nas videoaulas da disciplina. ${ }^{2}$ Os tutores acompanharam e orientaram tal processo, seguindo instruções detalhadas fornecidas pela docente. Como entrega final, os licenciandos fotografaram suas exsicatas e elaboraram um novo arquivo com seu Herbário Virtual. A qualidade do material produzido foi ótima e os estudantes mostraram-se bastante engajados e interessados na atividade. 


\section{Arte e história para abordar fotossintese}

Duas perspectivas, artística e histórica, foram utilizadas para contextualizar o tema fotossíntese na disciplina "Botânica" do curso da RedeFor. Realizamos inicialmente um fórum de discussão sobre o posicionamento polêmico de que os alunos não têm interesse pela botânica ou pela arte e, portanto, a contextualização baseada nesse enfoque não seria eficiente. A maioria dos cursistas se mostrou bastante contrária a tal ideia, discutindo diversas maneiras de unir essas duas temáticas. Apresentamos então a canção "Luz do Sol” (Caetano Veloso), sugerindo que os cursistas estabelecessem relações com a fotossíntese. Passamos a explorar o texto "Infinita beleza da fotossíntese" (Marcos Buckeridge), ${ }^{3}$ que aborda o processo de uma forma leve, relacionando-o a alguns trechos da canção. Os cursistas também estudaram o que chamamos de "Pinceladas históricas" sobre eventos relacionados à elucidação do processo de fotossíntese. Os participantes enfatizaram que a contextualização histórica raramente é associada ao tema e avaliaram a experiência de forma muito positiva. Finalmente, desenvolvemos e utilizamos uma animação interativa para o estudo dos processos propriamente ditos envolvidos na fotossíntese.

\section{Educação em Biodiversidade no Jalapão, TO}

O trabalho educativo e a pesquisa na região do Jalapão são desenvolvidos por um dos docentes da equipe e seus orientandos. Tem, como ponto de partida, a Educação em Biodiversidade, no contexto de Barker e Elliot (2000), adicionado dos contornos com que pretendemos implantá-la no país. Trabalhamos na perspectiva da coprodução do conhecimento; nela, as pessoas com as quais trabalhamos são, de fato, coparticipantes dos projetos. Essa perspectiva tem sido preconizada por plataformas internacionais de conservação e de sustentabilidade (como a Intergovernmental Science-Policy Platform on Biodiversity and Ecosystem Services - IPBES e a Future Earth) como um dos principais caminhos para que as populações locais efetivamente tornem-se parceiras e corresponsáveis nas ações de conservação e uso sustentável da biodiversidade.

Trabalhamos com duas comunidades quilombolas, Mumbuca e Prata, que vivem da extração e do artesanato produzido pelo uso de planta abundante nos campos úmidos locais, o capim-dourado (Syngonanthus nitens). Nossa expectativa é pesquisar os conhecimentos locais, as práticas de extrativismo e, sobretudo, conhecer o olhar e as concepções que as pessoas locais têm sobre o Cerrado e sua diversidade. Nosso objetivo, também, é o empoderamento dos coparticipantes, para que percebam que são responsáveis pelos próprios destinos e pelos destinos do local em que vivem, incluindo, aí, a biodiversidade. Dentre as várias iniciativas já desenvolvidas nas duas comunidades, relataremos três, todas numa perspectiva dialógica e promotoras do ensino-aprendizado contextualizado. Esperamos que, a partir delas, outras pessoas inspirem-se a juntar-se a nós. 


\section{O diálogo com as crianças}

Nosso objetivo foi pesquisar o olhar das crianças sobre o Cerrado. Queríamos conhecer os elementos que lhes traziam maior significado e quais eram ambientalmente percebidos com maior distinção. Nossa hipótese inicial era que, à semelhança do que ocorre com crianças de áreas urbanas, o universo zoológico seria mais percebido pelas crianças do Jalapão. Por meio de desenhos e suas narrativas, rodas de conversa e observação participativa, verificamos, porém, que o universo das plantas trazia, àquelas crianças, maior significado. As plantas são suas parceiras de brincadeiras e de descanso, proveem alimento e lazer. Constatamos um amplo conjunto de significados e de representações, associados ao mundo vegetal e ao seu conhecimento.

\section{Diálogo de saberes}

Nossa intenção era aproximar os conhecimentos científicos e os conhecimentos locais, empíricos, sobre as plantas utilizadas no artesanato com capim-dourado e buriti e, a partir disso, promover um diálogo de saberes (Tengö et al. 2014). Constatamos que muitas perguntas levantadas pela população local constituíam questões sobre as quais a botânica científica também se debruçava e que, em certa medida, havia aproximações significativas entre as diferentes fontes de conhecimento, o local e o científico. Por que o capim-dourado do Jalapão é mais dourado do que o dos outros locais? Por que usar a fibra extraída da folha do buriti-fêmea e não a do buriti-macho para o artesanato? Essas e outras questões foram levantadas, investigadas e, em certa medida, respondidas por todos os participantes: membros da comunidade científica e da comunidade de artesãs e artesões locais. Da perspectiva acadêmica, fomos enriquecidos com os conhecimentos locais e sua vivência cotidiana das plantas do Cerrado. Da perspectiva local, tivemos a oportunidade de mostrar aos nossos parceiros de pesquisa o universo do conhecimento científico: como ele é gerado e por quais instrumentos se chega a ele (Viana et al., 2014; 2018).

\section{Diálogo com as professoras}

A Secretaria de Educação do Tocantins determinou, nas escolas de comunidades quilombolas do estado, a criação de um componente curricular denominado "Saberes e Fazeres Quilombolas". Nesse contexto, pesquisadores acadêmicos e locais têm desenvolvido os conteúdos desse componente, a partir do resgate e das dinâmicas associadas aos saberes e fazeres locais. A perspectiva também é de pesquisa participativa e de coprodução do conhecimento. Verifica-se que os saberes e fazeres da comunidade da Mumbuca encontram-se fortemente atrelados ao ambiente e à biodiversidade local, em especial, às plantas, que se revelam protagonistas e elementos constitutivos da cultura e dos conhecimentos locais. Nesse contexto, a elaboração do componente curricular mostra-se como um processo de (re)construção da própria identidade, ligada ao ambiente e às plantas, como algo a ser ensinado e aprendido. 


\section{Trilha das Mudanças Climáticas Globais}

Relatamos uma iniciativa em rede do "Projeto Ecossistemas Costeiros do IB/CienTec/USP", que é o responsável pelo desenvolvimento de protocolos de ensino que são aplicados por Unidades de Conservação (UC) e escolas públicas do seu entorno (Berchez et al. 2005; 2016). Os protocolos dão diretrizes para uma ação educativa de caráter transdisciplinar (Max-Neef, 2005), unida aos conceitos de educação baseada em fenômenos e de ensino outdoor, onde o meio ambiente é utilizado como sala de aula e traz contextualização ao ensino.

O modelo "Trilha das Mudanças Climáticas Globais" permite discutir, dentro desse tema, todas as disciplinas de forma integrada por uma base ética. Objetiva-se a reflexão sobre a relação do processo de fotossíntese, fluxo de energia e ciclo do carbono com a formação dos combustíveis fósseis e sua posterior utilização para obtenção de energia. Em diferentes etapas, ao longo de um ano, prevê a formação dos professores de cada escola pública, de forma integrada para aplicação do tema e a formação prévia dos alunos por meio de cada um de seus professores, culminando na aplicação desses conhecimentos durante as visitas às UC.

A proposta de divisão de responsabilidades coloca a função do Projeto Ecossistemas Costeiros como: 1 criação e avaliação de protocolos; 2 formação e certificação de monitores; 3 intervenção nas escolas para formação dos professores. Propõe-se que cada UC parceira adote ao menos uma escola do entorno e viabilize ao menos a visita de uma classe, uma vez por ano, para realizar as atividades. Das escolas, espera-se que, com a ajuda dos monitores formados, realizem as atividades de estudo anteriores e posteriores à visita com seus alunos.

$\mathrm{Na}$ formação de monitores, pessoas ligadas às UC, alunos da USP e outros participantes recebem treinamento específico, ministrado pelo Projeto Ecossistemas Costeiros/USP. Tais integrantes são certificados de forma progressiva como estagiários de monitoria (em treinamento), monitores básicos (que recebem os alunos nas UC) ou monitores avançados (que participam do treinamento de professores e alunos, bem como da coordenação). Todos recebem carteira de identificação com foto para uso durante as atividades.

A intervenção nas escolas é feita por monitores avançados, apoiados por professores universitários, correspondendo, no início do ano, à apresentação da proposta para a coordenação pedagógica, seguida por workshop de formação de professores e curso de extensão com carga horária de 30 horas.

$\mathrm{Na}$ aplicação de protocolo durante a visita às UC, é realizada atividade guiada em trilhas curtas, em grupo de cinco pessoas, sendo o conteúdo interdisciplinar apresentado ao longo de estações com abordagens específicas, onde a atividade principal é uma gincana das mudanças climáticas globais, atividade lúdica e desafiadora, com participação ativa dos alunos e interferência dos monitores apenas pontualmente, a partir de réplicas.

Como atividade final, cada grupo de alunos que atuou em conjunto du- 
rante a visita à UC pode concorrer ao prêmio "Melhor Vídeo Sobre Mudanças Climáticas Globais", dentro de um subtema variável a cada ano, por meio do qual os estudantes se expressam e propagam sua opinião sobre o tema, dentro dos conceitos relacionados a educomunicação.

\section{Notas}

1 Disponível em: <www.botaniconline.com.br>.

2 Disponível em: <https://www.youtube.com/playlist?list=PLxI8Can9yAHf3Phl7g71V WAHc9rOVwRkN>.

3 Disponível em: <http://www.botanicaonline.com.br/site/14/pg7.asp>.

\section{Referências}

BALAS, B.; MOMSEN, J. L. Attention “Blinks" Differently for Plants and Animals. CBE - Life Sciences Education, v.13, p.437-43, 2014.

BARBOSA, P. P.; MACEDO, M.; URSI, S. Uso das Tecnologias de Informação e Comunicação (TIC) no ensino contextualizado de "Fotossíntese": uma proposta para o Ensino Médio. Revista da SBEnBio, v.9, p.2244-55, 2016.

BARKER, S.; ELLIOT, P. Planning a skills-based resource for Biodiversity Education. Journal of Biological Education, v.34, n.3, p.123-7, 2000.

BERCHEZ, F. A. S.; CARVALHAL, F.; ROBIM, M. J. Underwater Interpretative Trail - guidance to improve education and decrease ecological damage. International Journal of Environment and Sustainable Development, v.4, n.2, p.128-39, 2005.

BERCHEZ, F. A. S. et al. Marine and coastal environmental education in the context of global climate changes - synthesis and subsidies for ReBentos (Coastal Benthic Habitats Monitoring Network). Brazilian Journal of Oceanography, v.64, p.137-56, 2016.

BIZOTTO, F. M.; GHILARDI-LOPES, N. P.; MORPHY, C. D. S. A vida desconhecida das plantas: concepções de alunos do Ensino Superior sobre evolução e diversidade das plantas. Revista Electrónica de Enseñanza de las Ciencias, v.15, n.3, p.394-411, 2016.

BRANSFORD, J. D.; BROWN, A. L.; COCKING, R. R. Como as pessoas aprendem. Cérebro, mente, experiência e escola. São Paulo: Editora Senac, 2007.

BRASIL. Ministério de Educação e Cultura. Parâmetros Curriculares Nacionais: ensino médio. Brasília. MEC/SEMTEC, 1999.

- Ministério da Educação e Cultura. Orientações Curriculares para o Ensino Médio. Ciências da natureza, matemática e suas tecnologias. Brasília: MEC/SEB, 2006.

Ministério da Educação e Cultura. Base Nacional Comum Curricular. Secretaria da Educação Básica. Brasília: MEC/Consed/Undime, 2017.

CECCANTINI, G. T. Os tecidos vegetais têm três dimensões. Revista Brasileira de Botânica, v.29, n.2, p.335-7, 2006.

CHENOWETH, R. E.; GOBSTER, P. H. The nature and ecology of aesthetic experiences in the landscape. Landscape Journal, v.9, p.1-18, 1990. 
DANDALO, R. M.; LEME, J. S.; URSI, S. Biotecnologia Vegetal no Ensino Médio: uma proposta para estimular reflexões e tomada de decisão consciente. Revista da SBEnBio, v.7, p.4298-307, 2014.

FRANCO, C. O.; URSI, S. As plantas e sua exuberante diversidade: trabalhando com registros fotográficos na área verde do CEU EMEF Atlântica. Revista da SBEnBio, v.7, p.1220-9, 2014.

HERSHEY, D. R. A Historical Perspective on Problems in Botany Teaching. The American Biology Teacher, v.58, n.6, p.340-7, 1996.

Plant blindness: "we have met the enemy and he is us". Plant Science Bulletin, v.48, n.3, p.78-85, 2002.

HURD, P. D. Scientific Literacy: New Minds for a Changing World. Science Education, v.82, n.3, p.407-16, 1998.

KINOSHITA, L. S. et al. A Botânica no Ensino Básico: relatos de uma experiência transformadora. São Carlos: RiMa, 2006.

KRASILCHIK, M. Prática de Ensino de Biologia. 6.ed. São Paulo: Edusp, 2008.

MACEDO, M.; URSI, S. Botânica na Escola: uma proposta para o ensino de histologia vegetal. Revista da SBEnBio, v.9, p.2723-33, 2016.

MACEDO, M. et al. Concepções de professores de Biologia do Ensino Médio sobre o ensino-aprendizagem de Botânica. In: ANAIS DO IV EIBIEC. 2012, p.387-401.

MAX-NEEF, M. A. Foundations of transdisciplinarity. Ecological Economics, v.53, p.5$16,2005$.

MENEZES, E. T.; SANTOS, T. H. Verbete contextualização. Dicionário Interativo da Educação Brasileira - Educabrasil. São Paulo: Midiamix, 2001. Disponível em: <http://www.educabrasil.com.br/contextualizacao/>. Acesso em: 6 set. 2018.

NURSE, P. The Importance of Biology Education. Journal of Biological Education, v.50, n.1, p.7-9, 2016.

SALATINO, A.; BUCKERIDGE, M. "Mas de que te serve saber botânica?”. Estudos Avançados, v.30, n.87, p.177-96, 2016.

SANTOS, D. Y. A. C. et al. A botânica no cotidiano. Ribeirão Preto: Holos Editora, 2012.

SANTOS, F. S. A Botânica no Ensino Médio: será que é preciso apenas memorizar nomes de plantas? In: SILVA, C. C. (Org.) Estudos de História e Filosofia das Ciências. São Paulo: Editora Livraria da Física, 2006. p.223-243.

SENICIATO, T.; CAVASSAN, O. Ensino de ecologia e a experiência estética no ambiente natural: considerações preliminares. Ciência \& Educação, v.15, n.2, p.393-412, 2009.

SHULMAN, L. S. Those who understand: knowledge growth in teaching. Educational Researcher, v.15, n.4, p.4-14, 1986.

SILVA, J. N.; GHILARDI-LOPES, N. P. Botânica no Ensino Fundamental: diagnósticos de dificuldades no ensino e da percepção e representação da biodiversidade vegetal por estudantes de escolas da região metropolitana de São Paulo. Revista Electrónica de Enseñanza de las Ciencias, v.13, n.2, p.115-36. 2014. 
SILVA, J. R. S. Concepções dos professores de botânica sobre ensino e formação de professores. São Paulo, 2013. Tese (Doutorado) - Instituto de Biociências, Universidade de São Paulo. São Paulo, 2013.

SILVA, L. M.; CAVALlE, V. J.; AQUINI, Y. O professor, o aluno e o conteúdo no ensino da Botânica. Revista do Centro de Educação, v.31, n.1, p.67-80, 2006.

TENGÖ, M. et al. Connecting Diverse Knowledge Systems for Enhanced Ecosystem Governance: The Multiple Evidence Base Approach. AMBIO, v.43, n.5, p.579-91, 2014.

TOWATA, N.; URSI, S.; SANTOS, D. Y. A. C. Análise da percepção de licenciandos sobre o Ensino de Botânica na Educação Básica. Revista da SBEnBio, v.3, p.1603-12, 2010.

UNO, G. E. Botanical literacy: what and how should students learn about plants? American Journal of Botany, v.96, n.10, p.1753-9, 2009.

URSI, S. Possibilidades e desafios da formação inicial de professores na Educação a Distância: relato sobre uma disciplina de Práticas para o Ensino de Biologia. In: ANAIS DO III EREBIO - REGIONAL 1, 2017, p.52-57.

URSI, S.; BARBOSA, P. P. Fotossíntese: abordagem em um curso de formação docente continuada oferecido na modalidade Educação a Distância. Revista da SBEnBio, v.7, p.6198-208, 2014.

VIANA, R. V. R.; SANO P. T.; SCATENA V. L. Pesquisa de Campo como possibilidade de concretiza de diálogo: experiência em duas comunidades artesãs do Jalapão. Revista Desenvolvimento Social, n.13, p.57-67, 2014.

VIANA, R. V. R. et al. Engaging plant anatomy and local knowledge on the buriti palm (Mauritia flexuosa L.f.: Arecaceae): the microscopic world meets the golden grass artisan's perspective. Cultural Studies of Science Education, v.13, n.1, p.253-5, 2018.

WANDERSEE, J. H.; SCHUSSLER, E. E. Preventing plant blindness. The American Biology Teacher, v.61, p.84-6, 1999.

Toward a theory of plant blindness. Plant Science Bulletin, v.47, p.2-9, 2002.

WHITE, A. V. T. Guidelines for fields studies in Environmental Perception. Paris: Unesco/MAB, 1977.

RESUMO - O ensino de Botânica está inserido no contexto mais amplo da Educação Biológica. Contudo, apresenta peculiaridades que justificam uma análise mais cuidadosa e específica para suas questões. Realizamos reflexões sobre os objetivos, os desafios e as possibilidades para o enfoque dessa temática tão central na Educação Básica. Discutimos a importância da contextualização para promover o ensino de Botânica de boa qualidade, principalmente quando aliada à utilização de uma variedade de estratégias didáticas dinâmicas e que propiciem o interesse e protagonismo do estudante. Finalmente, enfatizamos a relevância da aproximação entre Universidade e Escola, apresentando experiências realizadas nesta perspectiva.

PALAVRAS-CHAVE: Ensino de Botânica, Contextualização, Formação de professores, Educação em Biodiversidade, Trilha das Mudanças Climáticas Globais. 
ABSTRACT - The teaching of Botany is inserted in the broader context of Biological Education. However, it presents some peculiarities that justify a careful and specific analysis of its issues. We reflect on the objectives, challenges and possibilities of focusing on this central theme in Basic Education. We discuss the importance of contextualization to promote quality teaching in Botany, especially when allied with the use of a variety of dynamic didactic strategies conducive to student interest and proaction. Finally, we emphasize the relevance of bringing together University and School, reporting some experiences related to this perspective.

KEYWORDS: Botany teaching, Contextualization, Teacher education, Biodiversity education, Trail of global climate changes.

Suzana Ursi é docente do Departamento de Botânica do Instituto de Biociências da Universidade de São Paulo. Coordena o BotEd - Grupo de Pesquisa Botânica na Educação. @-suzanaursi@usp.br

Percia Paiva Barbosa é doutoranda do Departamento de Botânica do Instituto de Biociências da Universidade de São Paulo. Participa do BotEd - Grupo de Pesquisa Botânica na Educação. @ - percia@usp.br

Paulo Takeo Sano é docente do Departamento de Botânica do Instituto de Biociências da Universidade de São Paulo. Coordena o grupo de Ensino em Biodiversidade (Laboratório de Taxonomia Vegetal). @-ptsano@usp.br

Flávio Augusto de Souza Berchez é docente do Departamento de Botânica do Instituto de Biociências da Universidade de São Paulo. Coordena o Projeto Ecossistemas Costeiros (Laboratório de Algas Marinhas). @ - fberchez@ib.usp.br

Recebido em 16.9.2018 e aceito em 5.10.2018.

I, II, III e IV Instituto de Biociências, Universidade de São Paulo, São Paulo, São Paulo, Brasil. 